Bangladesh J. Plant Taxon. 24(1): 13-22, 2017 (June)

(C) 2017 Bangladesh Association of Plant Taxonomists

\title{
MORPHOMETRIC ANALYSIS OF THE GENUS MONOCHORIA (PONTEDERIACEAE) IN SRI LANKA
}

\author{
Savithri Sarojani Udage and DeEPThi Yakandawala ${ }^{1}$ \\ Department of Botany, University of Peradeniya, Sri Lanka
}

Keywords: Monochoria vaginalis; Morphological data; Sub-palisade cavities; Principal coordinate anaysis.

\begin{abstract}
The genus Monochoria is represented in Sri Lanka by only two species, M. hastata and $M$. vaginalis. Of the two species $M$. vaginalis exhibits a high morphological diversity. A morphometric analysis was performed on the Sri Lankan members of the genus Monochoria to evaluate the morphological diversity exhibited by comparing 34 vegetative, anatomical and reproductive characters. Both cluster and principal coordinate analyses resulted in four clusters of which one corresponded to $M$. hastata, while $M$. vaginalis was divided into three phenetic groups indicating that the Sri Lankan $M$. vaginalis is a species complex involving more than one taxon. The length ratio of the lower spathe petiole to inflorescence stalk was identified as an informative character in delimiting the phenetic groups, a character that has not been considered before. Further, the occurrence of sub-palisade cavities that are filled with a red colored liquid in the leaves of two phenetic groups was a novel character for the genus as well as the family Pontederiaceae.
\end{abstract}

\section{Introduction}

The genus Monochoria C. Presl belongs to the family Pontederiaceae is distributed widely in the tropical and warm temperate regions of the Old world, Asia and Australia. Sri Lanka harbors two native members, Monochoria vaginalis (Burm. f.) C. Presl ex Kunth and M. hastata (L.) Solms (Dassanayake, 2000). The plants often inhabit wetlands and ditches, while M. vaginalis is more often found in paddy fields where it is considered a weed.

The taxonomy of the genus has been a point of debate and addressed by many taxonomists. Verdcourt (1961) in his taxonomic treatment to African Monochoria, recognized M. vaginalis as a species and raised the varieties then recognized under $M$. vaginalis to species rank, $M$. africana $\mathrm{N}$. E. Br. and M. brevipetiolata Verdc. Both are endemic to Africa. During the worldwide revision of the genus, Cook (1989) recognized eight species under the genus, M. korsakowii Regel \& Maack, M. vaginalis (Burm. f.) C. Presl ex Kunth, M. hastata (L.) Solms, M. elata Ridl., M. africana N.E.Br., M. brevipetiolata Verdc., M. cyanea (F. Muell.) F. Muell. and M. australasica Ridl. A comprehensive taxonomic treatment on Asian Monochoria by Wang et al. (2004) recognizes five species, M. korsakowii Regel \& Maack, M. hastata (L.) Solms, M. elata Ridl., M. valida G. X. Wang \& Nagam. and $M$. vaginalis (Burm.f.) Kunth. They also recognized two varieties of $M$. vaginalis, viz. M. vaginalis var. angustifolia $\mathrm{G}$. X. Wang and M. vaginalis var. vaginalis (Wang et al., 2004). The study however did not include any specimens from Sri Lanka.

According to Verdcourt (1961), the Asian, East African and West African populations of $M$. vaginalis belong to three distinct taxa. Wang et al. (2004) is of the opinion that the greater variability observed in the vegetative morphology of Monochoria due to adaptation to different

${ }^{1}$ Corresponding author. Email: deepthiy@pdn.ac.lk

DOI: http://dx.doi.org/10.3329/bjpt.v24i1.33001 
habitats may have led the early taxonomists to recognize 'species' and 'varieties'. A more recent study on Thai $M$. vaginalis also corroborates that the species exhibit a great variation in their morphology (Tungmunnithum, 2015). The studies using morphological and molecular data have indicated that $M$. vaginalis in Thailand consists of more than one taxon. The most recent taxonomic treatment on Sri Lankan Monochoria in the Revised Handbook to the Flora of Ceylon (Dassanayake, 2000) recognizes only two species: M. vaginalis and M. hastata. However, field studies recently carried out in Sri Lanka encountered M. vaginalis populations with distinct morphological characters and the results of a preliminary morphometric analysis by Udage and Yakandawala (2011) supported these observations. Therefore, the present study was carried out with the aim of re-evaluating the patterns of morphological variation within M. vaginalis and to understand the species limits of the genus Monochoria in Sri Lanka.

\section{Materials and Methods}

\section{Sample collection:}

Seventy-four live plant samples of Monochoria bearing flowers/fruits were collected, from populations of all possible locations in Sri Lanka, covering the three major climatic zones, wet, dry and intermediate zones. The specimens were then studied in detail. A reference collection of living plants was also maintained at the Department of Botany, University of Peradeniya, Sri Lanka during the study period (2010-2015).

\section{Data collection:}

The morphological features of the samples were studied in detail and recorded along with the characters traditionally used to identify and distinguish taxa within the genus. The morphological characters were examined and recorded from at least three specimens of a population. A minimum of five measurements were taken from an individual specimen for a particular character, and the mean measurement was taken as the particular character value. Macroscopic parts were observed under a dissecting microscope and a stereomicroscope (LEICA L2). The leaf anatomy was studied either with free hand sections or microtome sections. The microtome sections were stained in safranin. All character measurements were taken using a ruler (smallest measurement $1 \mathrm{~mm}$ ) or an eye piece graticule (smallest measurement $0.1 \mathrm{~mm}$ ) where appropriate. Following a preliminary examination of 88 characters, 34 characters ( 23 - quantitative and 11 - qualitative) were scored for the analysis based on the significance of variation (Table 1). The data were entered into an Excel spreadsheet (Microsoft Excel version 2007) and was later transformed into a file format suitable for morphometric analysis.

\section{Statistical analysis:}

The Principal Coordinate Analysis (PCoA) and the Hierarchical Cluster Analysis (CA) were carried out using the statistical software PAST (Version 2.15) (Hammer et al., 2001). The cluster solution was selected from the best suitable algorithm where, Gower Distance was used to calculate the similarity measures with the 'paired group' (UPGMA) option and the Single Linkage Algorithm with the highest Cophenetic Correlation Value. The ordination analysis was performed with Gower Distance (transformation exponent $\mathrm{C}=2$ ) to generate a distance matrix for the use in the PCoA. Since the PCoA gives the distance between the OTU's rather than the correlation between characters, this is suitable for a mixed character data, as it will not be distorted by binary characters as with Principal Components Analysis (PCA) (Cupido, 2003). From the results of these analyses, each major, consistently recovered clusters were identified. 


\section{Results and Discussion}

The UPGMA dendrogram (cophenetic correlation coefficient $=0.8587$ ) resolved four discrete clusters of OTUs (hereafter referred to as Phenetic Groups 1-4), which separated respectively at approximately $0.425,0.35$, and 0.225 distance units (Fig.1). The first four (principal) eigenvalues recovered from the PCoA $(2.4495,0.4264,0.2390$ and 0.1286$)$ accounted for $74.456 \%$ of the total

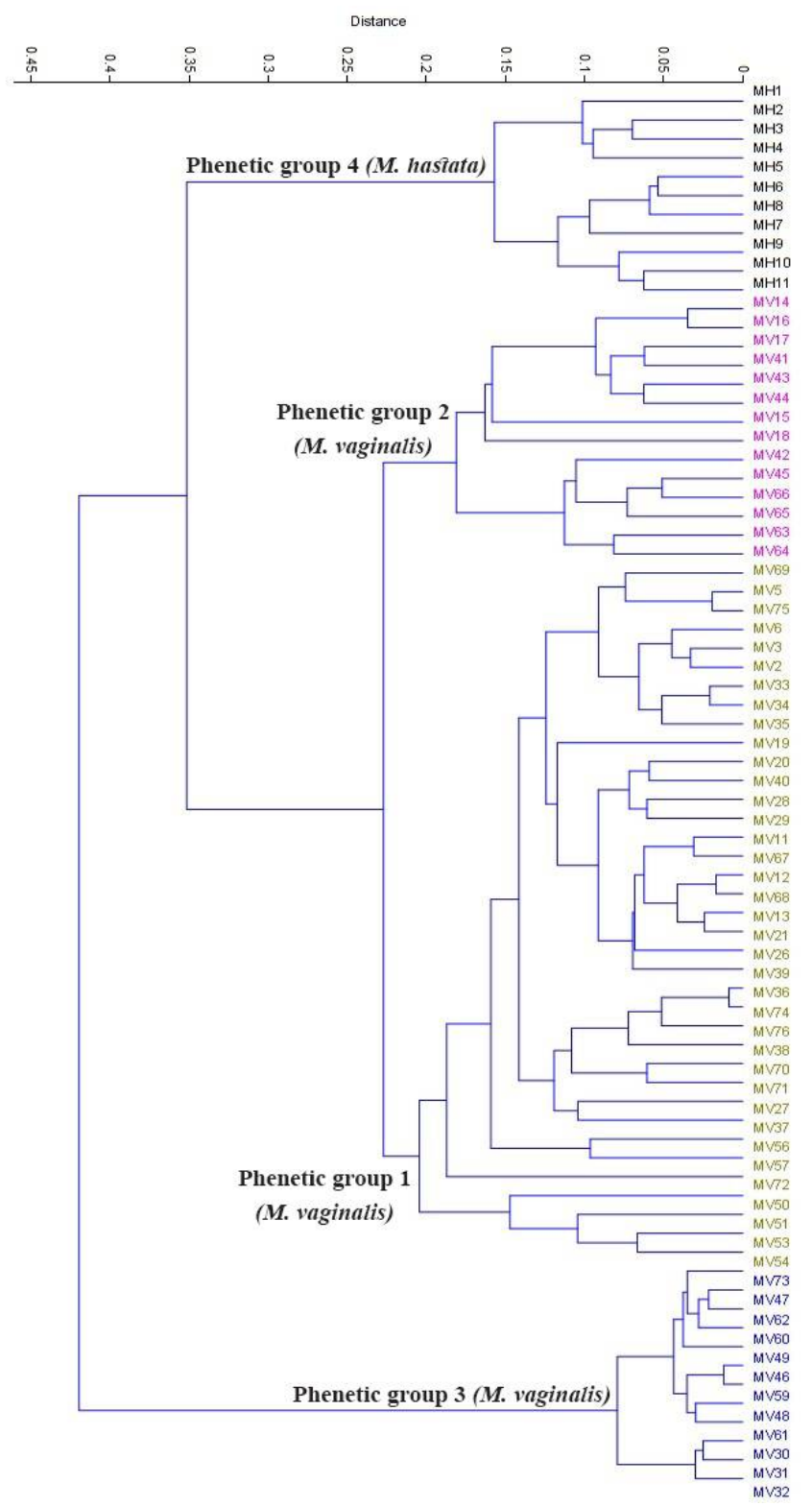

Fig. 1. Dendrogram resulted from Cluster analysis of OTUs of Monochoria in the morphometric analysis. The OTUs corresponding to the three clusters of $M$. vaginalis are marked as $M$. vaginalis Phenetic Groups 1, 2 and 3. 
variance $(56 \%, 9.79 \%, 5.49 \%$ and $2.954 \%$ respectively). A plot of the first and second coordinates (which provided the greatest separation of OTUs) resulted in a separation similar to that obtained by the CA. Here the PCoA also resolved four discrete clusters (Fig.2) with each corresponding exactly to one of the clusters indicated by the UPGMA dendrogram (Fig.1). However, few members of the Phenetic Groups 1 and 2 overlapped along both first and second coordinate axes (Fig.2).

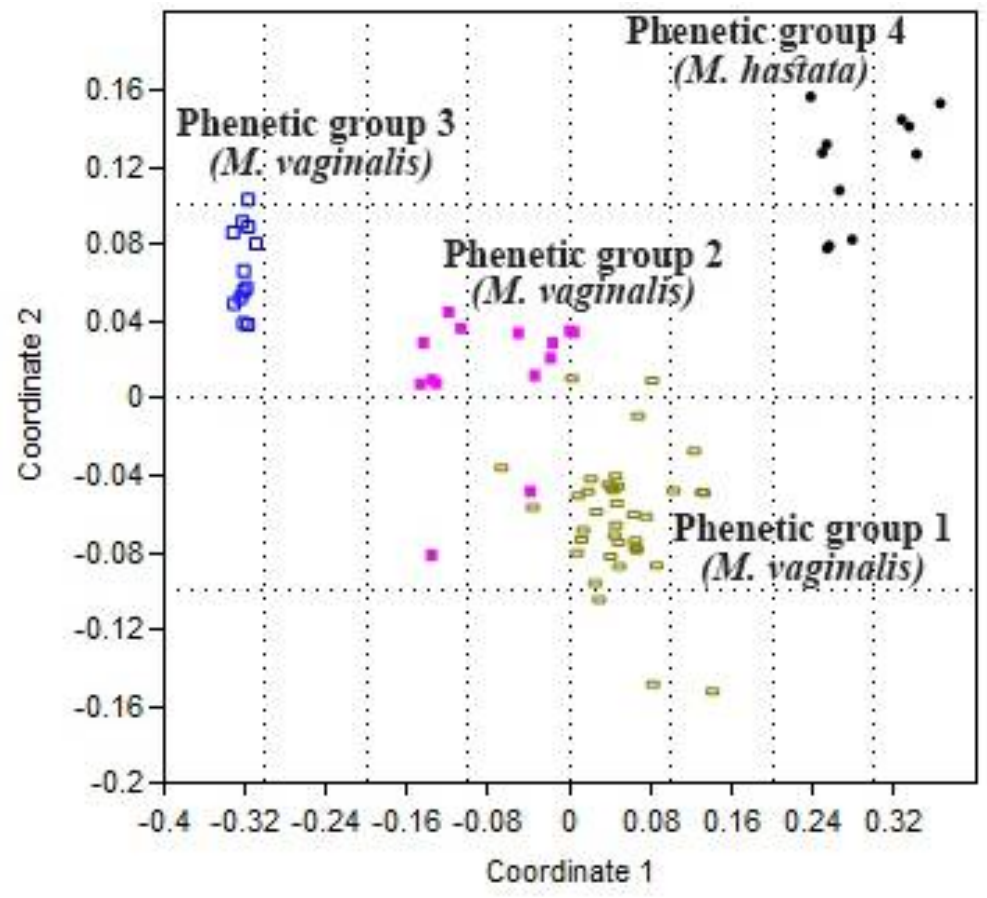

Fig. 2. Scatter plot resulted from PCoA showing the four distinct phenetic groups of Monochoria OTUs generated from the evaluated study material.

The Cluster Analysis and the PCoA recognized $M$. hastata as a distinct group while dividing the OTU's of $M$. vaginalis into three distinct clusters, indicating the involvement of more than one phenetic group within M. vaginalis in Sri Lanka. The significant differences in leaf lobe length and inner and outer tepal widths separate the three phenetic groups of $M$. vaginalis from each other. The variations in leaf width and the position where the inflorescence arose (length ratio of the lower spathe petiole: inflorescence stalk) clearly separated the Phenetic Group 1 from the other two groups. The differences in flower diameter, inner and outer tepal lengths and inner and outer tepal widths contributed to the separation of the Phenetic Group 3 from the other two groups. The ranges of other characters overlapped among the three phenetic groups (Table 2).

The Phenetic or multivariate methods in taxonomic studies provide insights on how to interpret phenetic results to make valid taxonomic decisions. In the absence of a universally acceptable species concept, it is up to the individual taxonomist to define species level taxa (Davis and Goldman, 1993; Cupido, 2003). The phenetic species concept of Sneath and Sokal (1973) is an empirical method that considers distinct phenetic clusters produced by overall similarity as species, without making assumptions about speciation. Clusters of overall similarity are formed between objects as a function of their individual similarities in each of the many characters in 
which they are being compared. These phenetic clusters possess a group of partially correlated characters rather than a fixed character and therefore pattern related. The pattern related species concepts are feasible for practicing taxonomists because they use criteria that are based on observed patterns of character variation in delineating species (Cupido, 2003).

Table 1. List of characters used in the multivariate analysis.

\begin{tabular}{|c|c|c|c|}
\hline & Quantitative characters & & Qualitative characters \\
\hline 1 & Plant height up to leaf base & 1 & Leaf shape \\
\hline 2 & Leaf width & 2 & Leaf base \\
\hline 3 & Leaf length - lamina & 3 & Lamina texture \\
\hline 4 & Leaf length - lobe & 4 & $\begin{array}{l}\text { Presence of sub palisade cavities filled } \\
\text { with a red liquid filled with a }\end{array}$ \\
\hline 5 & Peduncle length & 5 & $\begin{array}{l}\text { Arrangement of flowers in the } \\
\text { inflorescence }\end{array}$ \\
\hline 6 & Peduncle width & 6 & Bract shape \\
\hline 7 & $\begin{array}{l}\text { Length ratio of the lower spathe } \\
\text { petiole: inflorescence stalk }\end{array}$ & 7 & Bract texture \\
\hline 8 & Number of flowers per inflorescence & 8 & Flower color \\
\hline 9 & Bract width & 9 & Persistent perianth surrounding the capsule \\
\hline 10 & Bract length & 10 & Persistent tepal texture in capsule \\
\hline 11 & Pedicel length & 11 & Capsule shape \\
\hline 12 & Pedicel width & & \\
\hline 13 & Flower diameter & & \\
\hline 14 & Outer tepal length & & \\
\hline 15 & Outer tepal width & & \\
\hline 16 & Inner tepal length & & \\
\hline 17 & Inner tepal width & & \\
\hline 18 & Style length & & \\
\hline 19 & Ovary length & & \\
\hline 20 & Anther length of large stamen & & \\
\hline 21 & Filament length of large stamen & & \\
\hline 22 & Anther length of small stamen & & \\
\hline 23 & Filament length of small stamen & & \\
\hline
\end{tabular}

The results of the morphometric analyses, CA and PCoA, further suggest that the Sri Lankan $M$. vaginalis sens. lat. may be a species complex with three different phenetic groups. These were recognized from the analyses as M. vaginalis Phenetic Group 1, M. vaginalis Phenetic Group 2 and $M$. vaginalis Phenetic Group 3 supporting the field observations made during the past years. The comparison of morphological features with those in the published literature, tentatively identified the Phenetic Group 1 as $M$. vaginalis but would still need confirmation by scoring type specimens of $M$. vaginalis and conducting phylogenetic analyses. None of the phenetic groups exhibited features of M. vaginalis var. angustifolia recognized by Wang et al. (2004) on the basis of having narrow lanceolate mature leaves, $3-7 \times 0.3-2.0 \mathrm{~cm}$ with the basal lobes up to $0.2 \mathrm{~cm}$ long, apex acute or acuminate and 3-7 flowered raceme.

Although the vegetative characters of Monochoria are highly variable, even within a single species, many of them have proven to be of taxonomic significance. Wang et al. (2004) discuss the taxonomic utility of some of these morphological features in detail. The leaf characters such as length, width and the basal lobe length were taxonomically useful characters in the study of Asian Monochoria (Wang et al., 2004). Similarly, they were useful in the present study in delimiting the already recognized $M$. hastata and the putative phenetic groups within M. vaginalis. The Phenetic 
Group 1 which is tentatively identified as $M$. vaginalis, exhibited the shortest basal leaf lobe with a shallow sinus compared to the other two phenetic groups.

Table 2. Comparison of distinct morphological characters among the three phenetic groups of $M$. vaginalis and $M$. hastata.

\begin{tabular}{|c|c|c|c|c|}
\hline Character & $\begin{array}{l}\text { M. vaginalis } \\
\text { phenotype } 1\end{array}$ & $\begin{array}{l}\text { M. vaginalis } \\
\text { phenotype } 2\end{array}$ & $\begin{array}{l}\text { M. vaginalis } \\
\text { phenotype } 3\end{array}$ & M. hastate \\
\hline $\begin{array}{l}\text { Leaf length }(\mathrm{cm}) \\
\text { (Excluding the lobes) }\end{array}$ & $3.8-9.3$ & $5.6-14.9$ & $5.1-7.6$ & $5.9-12.9$ \\
\hline Leaf lobe length $(\mathrm{cm})$ & $0.2-0.8$ & $1.8-2.6$ & $0.9-1.7$ & $2.2-3.5$ \\
\hline $\begin{array}{l}\text { Leaf width }(\mathrm{cm}) \\
\text { (at the broadest point) }\end{array}$ & $2.4-6.6$ & $5.4-7.5$ & $5.1-8.1$ & $4.3-6.7$ \\
\hline Leaf shape & $\begin{array}{l}\text { Ovate - lance } \\
\text { ovate }\end{array}$ & Widely ovate & Widely ovate & Ovate - lance ovate \\
\hline Leaf base & $\begin{array}{l}\text { Cordate with a } \\
\text { shallow sinus }\end{array}$ & $\begin{array}{l}\text { Cordate with a } \\
\text { deep sinus }\end{array}$ & $\begin{array}{l}\text { Cordate with a } \\
\text { large sinus }\end{array}$ & Sagittate \\
\hline Lamina texture & Smooth & Relatively thick & $\begin{array}{l}\text { Rough upper } \\
\text { surface }\end{array}$ & Smooth \\
\hline $\begin{array}{l}\text { Sub palisade cavities filled } \\
\text { with a red liquid }\end{array}$ & Absent & $\begin{array}{l}\text { Occasionally } \\
\text { present }\end{array}$ & Present & Absent \\
\hline $\begin{array}{l}\text { The length ratio of the } \\
\text { lower spathe petiole: } \\
\text { inflorescence stalk }\end{array}$ & $(1: 2)-(1: 3)$ & $1: 1$ & $1: 1$ & $1: 4$ \\
\hline $\begin{array}{l}\text { Number of flowers per } \\
\text { inflorescence }\end{array}$ & $5-11$ & $15-19$ & $10-19$ & $12-51$ \\
\hline Flower arrangement & Lax & Dense & Dense & $\begin{array}{l}\text { Dense (helically } \\
\text { arranged) }\end{array}$ \\
\hline Peduncle length $(\mathrm{cm})$ & $1.5-3.0$ & $1.0-1.4$ & $1.0-1.4$ & $2.0-2.5$ \\
\hline Flower diameter $(\mathrm{cm})$ & $1.6-2.7$ & $1.6-2.7$ & $0.8-1.5$ & $1.9-2.9$ \\
\hline Pedicel length $(\mathrm{cm})$ & $0.5-2.0$ & $0.5-2.0$ & $0.1-0.4$ & $1.2-3.5$ \\
\hline $\begin{array}{l}\text { Arrangement of the } \\
\text { persistent perianth around } \\
\text { the capsule }\end{array}$ & $\begin{array}{l}\text { Irregularly } \\
\text { twisted around } \\
\text { ripe fruit }\end{array}$ & $\begin{array}{l}\text { Irregularly } \\
\text { twisted around } \\
\text { ripe fruit }\end{array}$ & $\begin{array}{l}\text { Not twisted, } \\
\text { but partially } \\
\text { covers the } \\
\text { capsule }\end{array}$ & $\begin{array}{l}\text { Twisted and } \\
\text { screwed on the ripe } \\
\text { fruit in a regular } \\
\text { manner }\end{array}$ \\
\hline $\begin{array}{l}\text { Capsule shape } \\
\text { seed shape }\end{array}$ & $\begin{array}{l}\text { Widely elliptic } \\
\text { Oblong }\end{array}$ & $\begin{array}{l}\text { Widely elliptic } \\
\text { Widely elliptic }\end{array}$ & $\begin{array}{l}\text { Ovate } \\
\text { Widely elliptic }\end{array}$ & $\begin{array}{l}\text { Widely elliptic } \\
\text { Oblong }\end{array}$ \\
\hline
\end{tabular}

In addition, the sub-palisade cavities that are filled with a red coloured liquid were observed in the leaves of the Phenetic Groups 3 and 2 (to a lesser extent in Group 2). This character is a novel character for the genus Monochoria and the family Pontederiaceae. The leaf surface of the phenetic group 3 was rough or blister like; the blisters are visible to the naked eye as well as under the stereomicroscope (Fig. 4). Therefore, the presence of sub-palisade cavities filled with a red coloured liquid seems to be a taxonomically important character in delimiting the entities within $M$. vaginalis sens. lat. Although the sub-palisade cavities were recorded in our study, a recent study on comparative anatomical characteristics of M. vaginalis and M. hastata conducted in India (Narayanan and Kaliappan, 2014) did not record any cavities/glands in the sub-palisade layer. The populations of the Phenetic Group 3 were mostly distributed in the dry zone of Sri Lanka but several co-occurring populations of Phenetic Groups 1 and 3 were also encountered. The populations of the Phenetic Group 2 were relatively restricted in their distribution. 
The floral features including inflorescence characters were also of taxonomic importance in the genus Monochoria. Monochoria occurring in Asia possess sub-umbellate inflorescences, racemes or branched panicles (Cook, 1989; Wang et al., 2004). Of the two species occurring in Sri Lanka, $M$. hastata possesses a sub-umbellate inflorescence, while $M$. vaginalis possesses a raceme type inflorescence. According to Wang et al. (2004), the flowering sequence of M. hastata is definite while it is indefinite blooming in M. vaginalis. However, according to the field observations, inflorescences of all specimens encountered under M. vaginalis in Sri Lanka show a definite sequence in the blooming pattern. This observation corroborates with few other literature. Although Trimen (1898) identified the inflorescence type of M. vaginalis as a sub-sessile raceme, he states that the terminal flower is the first to open. Further, Soerjani et al. (1987) also state that the inflorescence is a raceme and flowers open either simultaneously or from top to bottom within a few days. Most literature does not mention the flower opening sequence of Monochoria. The inflorescence of $M$. vaginalis Phenetic Group 1 was lax, whereas it was dense in the other two phenetic groups. The flower diameter was larger $(1.6-2.7 \mathrm{~cm})$ in the M. vaginalis Phenetic Groups 1 and 2, while that of the Phenetic Group 3 was relatively smaller $(0.8-1.5 \mathrm{~cm})$.
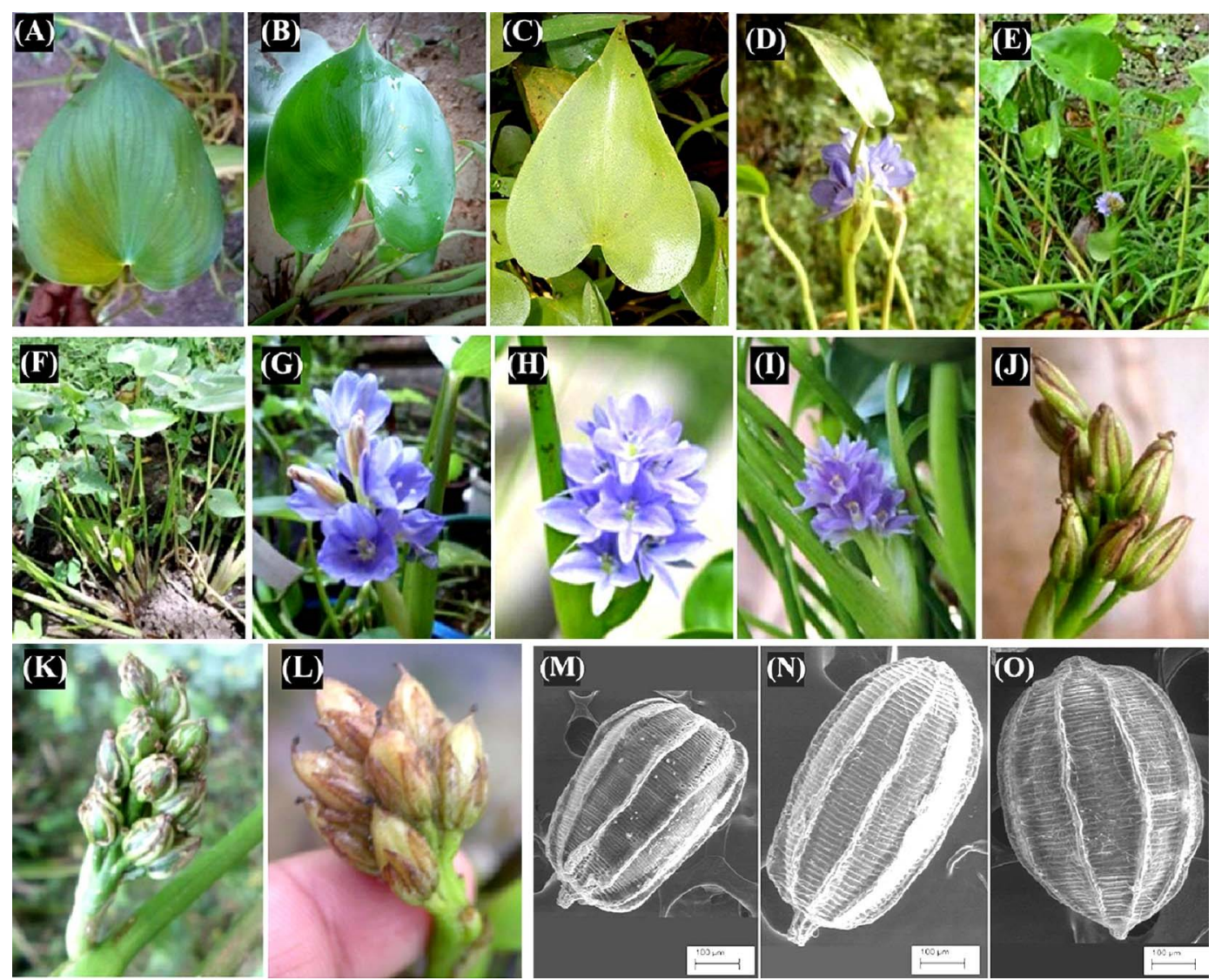

Fig. 3. Comparison of the morphological characters among the three phenetic groups: leaves, proportion of the lower spathe petiole: inflorescence stalk, inflorescence, fruits and seeds of Phenetic Group 1 (A, D, G, J, M) Phenetic Group 2 (B, E, H, K, N) and Phenetic Group 3 (C, F, I, L, O) respectively. 
During the present study, the position from where the inflorescence arose was taxonomically informative i.e. the length ratio of the lower spathe petiole: inflorescence stalk. This character was not taken into account in previous taxonomic treatments. The inflorescence of Monochoria is terminal where it is subtended by two spathes, upper and lower. In both M. vaginalis and $M$. hastata, the upper spathe is reduced. In M. vaginalis (Phenetic Group 1) this proportion was between 1:2 - 1:3 where the inflorescence arose closer to the lower spathe. In the other two Phenetic groups ( 2 and 3 ) it was 1:1 or even more towards the base of the plant. Further, during this study we did not encounter specimens with the petiole length of the lower spathe was as short as $0.5 \mathrm{~cm}$ as recorded by Cook (1989).
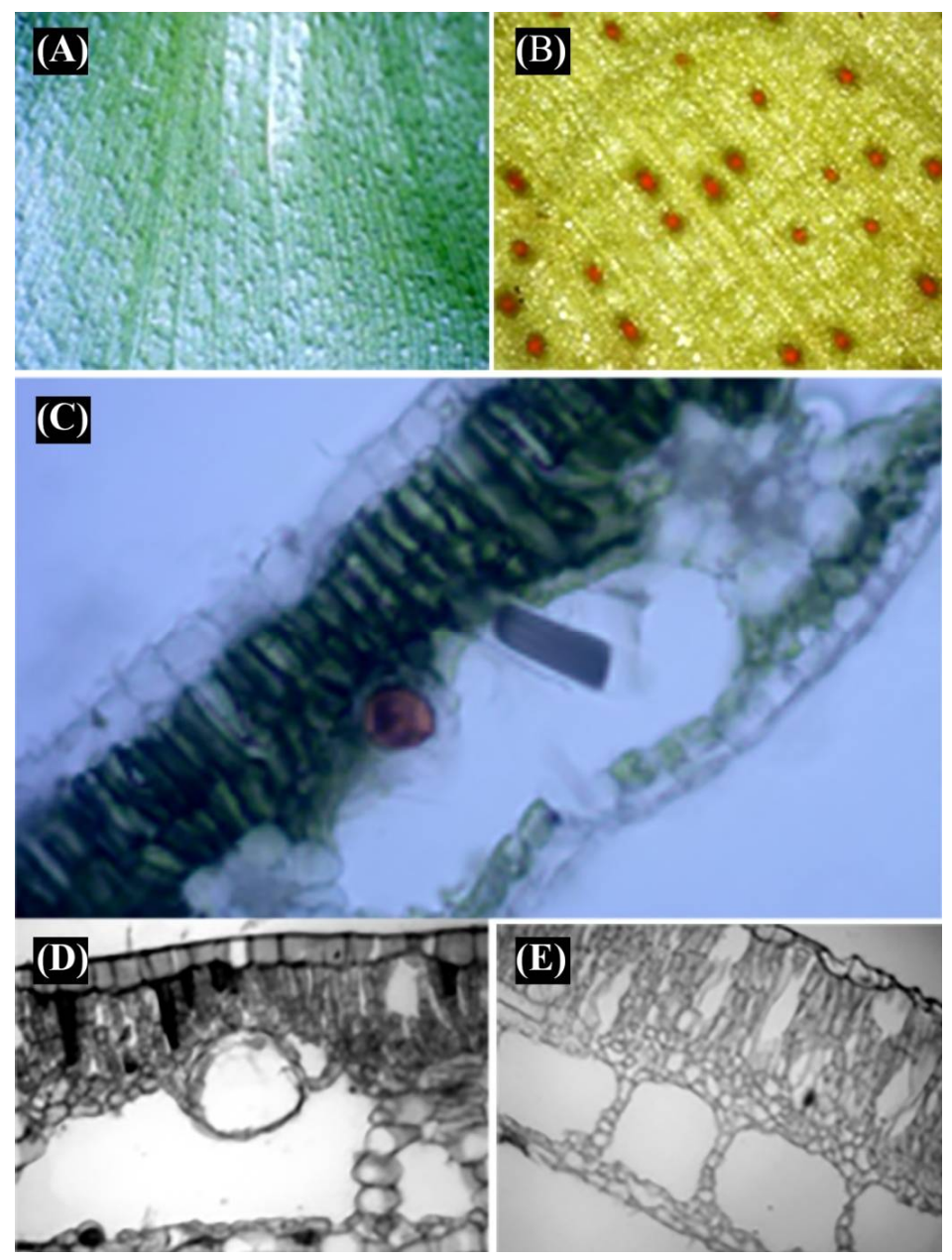

Fig. 4. Sub-epidermal glands in the Phenetic group 3. (A): Leaf upper surface, the glands are visible as blisters; (B): Leaf upper surface under a stereomicroscope, the glands are visible as red dots; (C): Leaf section under the light microscope (x10x10); (D): Leaf sections (Microtome) under the light microscope (x10) and (E): Leaf sections (Microtome) of Phenetic group 1 with no glands under the light microscope (x10). 
Fruit and seed characters were also of taxonomic importance in the genus Monochoria. The capsule of Monochoria is usually covered by a persistent perianth. The persistent tepals/perianth of M. hastata is screwed, covering the fruit, while in M. vaginalis Phenetic Group 1 and Phenetic Group 2, the perianth parts are arranged spirally but not neatly screwed. In Phenetic Group 3, the perianth parts do not totally cover the fruit. Even though not included in the analysis, the examination of seeds of a larger subset of individuals indicates that the seed shapes are also taxonomically useful in recognition of the three phenetic groups within M. vaginalis in Sri Lanka (

Fig. 3). The three $M$. vaginalis phenetic groups showed variation in the seed size and shape; seeds of the Phenetic Group 1 were the largest $(0.834-0.869$ x $0.594-0.617 \mathrm{~mm})$ while Group 3 seeds were the smallest $(0.393-0.399 \times 0.280-0.301 \mathrm{~mm})$. The chalazal end of M. vaginalis Phenetic Group 1 was depressed while that in the other two groups was obtuse.

The results of the multivariate analyses of morphological data suggest that the Sri Lankan $M$. vaginalis sens. lat. is a species complex that includes two distinct phenetic groups as well as the true $M$. vaginalis. These phenetic groups have also been supported by molecular studies using RAPD data (Jayewardene et al. (2013 and Gunaratne et al. (2014) where the polymorphic banding patterns were different among the three $M$. vaginalis phenetic groups. Moreover, a phytochemical investigation by Ileperuma et al. (2014) reported different chemical profiles for the three phenetic groups of $M$. vaginalis. The Phenetic Group 3 with the sub-palisade cavities expressed a chemical profile with the highest brine shrimp lethality/toxicity and haemolytic activity which could possibly be abbreviated to the chemical substances deposited. Further, the results of the present study were similar to the results of the recent study conducted in Thailand (Tungmunnithum, 2015), in which a taxonomic revision was carried out to evaluate the species limits of M. vaginalis and the results indicated the involvement of more than one taxon within the species.

Resolving the species circumscriptions is important in terms of evaluating the biodiversity and its conservation. It is feared that many species will become extinct even before they are described due to clearing and destruction happening around the world. In order to conserve the species and their diversity, scientists should be able to correctly identify the species, locate their populations and estimate the remaining extents of those populations. To support the correct taxonomic identification, species complexes such as Monochoria vaginalis sens. lat. should be studied in detail and taxonomic species boundaries should be defined. The present study contributes to understanding the diversity and the putative number of entities within Monochoria vaginalis sens. lat. M. vaginalis is an important medicinal plant and the identification of the correct species with the expected medicinal value is a requisite. Further studies of Sri Lankan $M$. vaginalis using molecular data are currently underway and expectantly will shed additional merit in the identification of the M. vaginalis and the description of species corresponding with the phenetic groups. In addition, once the species limits are resolved, revised taxonomic keys will be developed to correctly identify the species.

\section{References}

Cook, C.D.K. 1989. Taxonomic revision of Monochoria (Pontederiaceae). In: Tan, K (Ed). The Davis and Hedge Festschrift: Plant taxonomy, phytogeography and related subjects. Edinburgh, University Press. pp. 149-184.

Cupido, C.N. 2003. Systematic studies in the genus Merciera (Campanulaceae): A re-assessment of species boundaries. Adansonia 25(1): 33-44.

Dassanayake, M. D. 2000. Pontederiaceae. In: Dassanayake, M.D. and Clayton W.D. (Eds.), A Revised Handbook to the Flora of Ceylon 14. Oxford \& IBH Publishing Co. Pvt. Ltd., New Delhi, pp. 259-264. 
Davis, J.I. and Goldman, D.H. 1993. Isozyme variation and species delimitation among diploid populations of the Puccinellia nuttalliana complex (Poaceae): character fixation and the discovery of phylogenetic species. Taxon 42: 585-599.

Gunaratne, U.S., Samaraweera, P. and Yakandawala, D.M.D. 2014. Genetic diversity among populations of Monochoria vaginalis detected by random amplified polymorphic DNA (RAPD) validates three phenetic groups found in Sri Lanka. Proceedings of The Peradeniya University International Research Sessions, iPURSE - 2014.Peradeniya, Sri Lanka 18. p. 610 (Abs.)

Hammer, Ø., Harper, D.A.T. and Ryan, P.D. 2001. PAST: Paleontological statistics software package for education and data analysis. Palaeontol. Electronica 4: 1-9.

Ileperuma, C.V.K., Jayasinghe, U.L.B., Yakandawala, D.M.D. and Kumar, N.S. 2014. A re-assessment of species boundaries of the genus Monochoria (Pontederiaceae) in Sri Lanka using phytochemical data. Proceedings of the Peradeniya University International Research Sessions, iPURSE - 2014, Peradeniya, Sri Lanka 18, p 589 (Abs.)

Jayawardhana, B.J.G., Samaraweera P. and Yakandawala, D.M.D. 2013. Genetic Diversity of Monochoria vaginalis in Sri Lanka by using Random Amplified Polymorphic DNA (RAPD) Markers. Proceedings and abstracts of the Peradeniya University Research Sessions, PURSE - 2012, Peradeniya, Sri Lanka 17(1), P 247 (Abs.)

Narayanan, K. B. and Kaliappan, I. 2014. Comparative Anatomical Characteristics of Emergent Aquatic HerbsMonochoria vaginalis (Burm. F.) Presl. and Monochoria hastata Solms. (Pontederiaceae). International Journal of Botany, 10: 13-23. DOI: 10.3923/ijb.2014.13.23.

Sneath, P.H.A. and Sokal, R.R. 1973. Numerical taxonomy: the principles and practice of numerical classification. W.H. Freeman \& Co., San Francisco.

Soerjani, M., Kostermans, A.J.G.H. and Tjitrosoepomo, G. 1987. Weeds of rice in Indonesia. Balai Pustaka, Jakarta, Indonesia. pp. $484-489$.

Trimen, H. 1898. A Handbook to the Flora of Ceylon Part 4, Dulau \& Co. London, 295 -296.

Tungmunnithum, Duangiai 2015. Morphological and Molecular Evidences of the Greatest Variable Monochoria Species in Thailand. BOTANY 2015, July 25 - 29, 2015, The Shaw Conference Centre Edmonton, Alberta, Canada.

Udage, S. and Yakandawala, D. 2011. Morphological variation and species boundaries of the genus Monochoria (Pontederiaceae) in Sri Lanka. Proceedings of the Peradeniya University Research Sessions, PURSE - 2011, Peradeniya, Sri Lanka 16 (1): 189.

Verdcourt, B. 1961. The genus Monochoria Presl (Pontederiaceae) in Africa. Kirkia 1: 80-83.

Wang, G-X., Wei, L, Xiao-Chun, W. and Itoh, K. 2004. Taxonomy of the genus Monochoria (Pontederiaceae) in Asia. Current Topics in Plant Biology 5: 39-52. 